\section{SAT0185 BIO-HOLIDAY THERAPY WITH A TIGHT CONTROL STRATEGY IN RHEUMATOID ARTHRITIS PATIENTS WITH CLINICAL DISEASE ACTIVITY INDEX REMISSION ENABLES MAINTENANCE OF BONE METABOLISM STATUS}

E. Torikai, M. Suzuki, Y. Matsuyama. Orthopaedic Surgery, Hamamatsu University School of Medicine, Hamamatsu, Japan

Background: The cost of Bio therapy has become a major problem in health economics and is unaffordable for some patients. Thus, it is important to consider whether we should discontinue or extend the interval of Bio. At EULAR 2016, we reported that maintaining disease activity, radiographic progression, and physical function via Bio-holiday therapy in rheumatoid arthritis (RA) patients with clinical disease activity index (CDAl) remission under a tight control strategy is possible. Osteoporosis is another issue for RA patients. RA patients generally develop osteoporosis more frequently than healthy individuals because of increased bone resorption and inhibited bone formation.

Objectives: To investigate bone metabolism markers and bone mass index of RA patients with CDAI remission who underwent Bio-holiday therapy.

Methods: Sixty-four RA patients with CDAI remission were included and were classified into two groups. Bio-holiday group (group H) comprised 34 patients [golimumab (GLM) and tocilizumab (TCZ), 18 and 16 patients, respectively] and in which patients were taken off Bio if they achieved CDAI remission. Patients visited our clinic at least once every 2 months and were treated with Bio within 3 months after falling out of CDAl remission. They could be taken off Bio again when they reached CDAl remission. The Bio group (group C) comprised 30 patients (GLM and TCZ, 16 and 14 patients, respectively). The mean ages of groups $\mathrm{H}$ and $\mathrm{C}$ were 52.9 and 55.6 years, respectively, and the mean disease durations were 3.98 and 4.13 years, respectively. There were no statistical differences between the backgrounds of the two groups. We compared the change in bone metabolism makers [urine type I collagen cross-linked N-telopeptide (NTX), serum tartrate-resistant acid phosphatase 5b (TRACP5b), serum bone-specific alkaline phosphatase (BAP), and serum osteocalcin (OC)] and bone mineral density (BMD) of lumber spine (L-spine) and femoral neck (FN) between both groups for 2 years. Results: The mean withdrawal periods were 12.1 and 8.8 months with GLM and TCZ, respectively. Three and four patients dropped out because of financial constraints in the in the groups $\mathrm{H}$ and $\mathrm{C}$, respectively. One patient in each group dropped out because of RA flare-up. No patients in either group discontinued their therapy because of adverse events. Besides one patient who dropped out because of RA flare-up, all remaining patients in the group $\mathrm{H}$ were able to achieve CDAI remission without delay. There were no statistical differences in CDAl throughout the study period (Fig.1). There were no statistical differences in any of the bone metabolism makers throughout the study period (Table.1) and BMD of L-spine (Fig. 2(a)) and FN (Fig. 2(b)) at baseline and last evaluation.

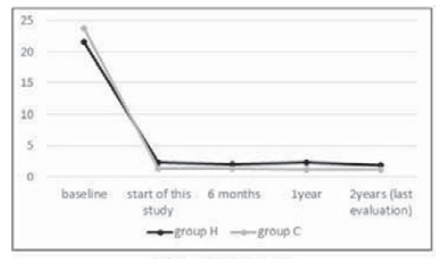

Fig.1 CDAl score

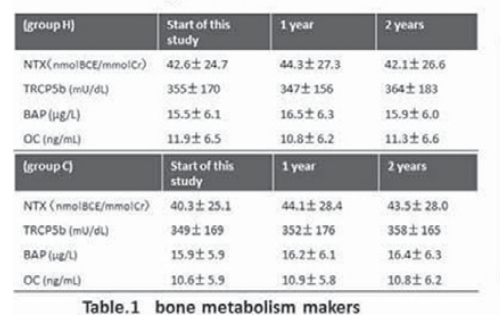

Table.1 bone metabolism makers

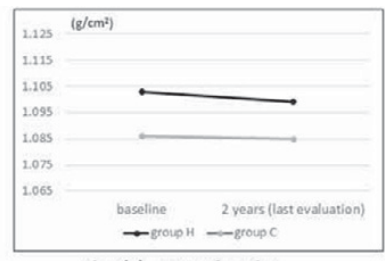

Fig.2(a) BMD of L-spine

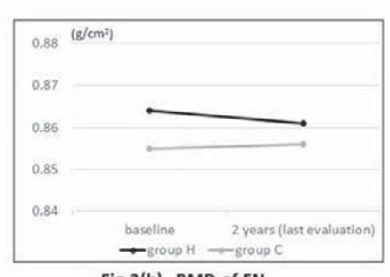

Fig.2(b) BMD of FN
Conclusions: We conclude that maintaining disease activity bone metabolism status via Bio-holiday therapy for RA patients with CDAI remission under a tight control strategy is possible. Given that the flare-up rate in RA patients with deep remission is not high, it is not difficult to resume Bio therapy and gain CDAl remission. Furthermore, this treatment is financially durable. Therefore, we recommend Bio-holiday therapy.

Disclosure of Interest: None declared

DOI: 10.1136/annrheumdis-2017-eular.2088

\section{SAT0186 EFFECTS OF DENOSUMAB, A SUBCUTANEOUS RANKL INHIBITOR, ON THE PROGRESSION OF STRUCTURAL DAMAGE IN JAPANESE PATIENTS WITH RHEUMATOID ARTHRITIS TREATED WITH CSDMARDS: RESULTS FROM THE 12-MONTH DOUBLE BLIND PHASE 3, DESIRABLE STUDY \\ T. Takeuchi ${ }^{1}$, Y. Tanaka ${ }^{2}$, S. Soen ${ }^{3}$, H. Yamanaka ${ }^{4}$, T. Yoneda $^{5}$, S. Tanaka ${ }^{6}$,} T. Nitta ${ }^{7}$, N. Okubo ${ }^{7}$, H.K. Genant ${ }^{8}$, D. van der Heijde ${ }^{9} .{ }^{1}$ Keio University School of Medicine, Tokyo: ${ }^{2}$ University of Occupational and Environmental Health, Kitakyushu; ${ }^{3}$ Kindai University Nara Hospital, Ikoma; ${ }^{4}$ Institute of Rheumatology Tokyo Women's Medical University, Tokyo, Japan; ${ }^{5}$ Indiana University School of Medicine, Indianapolis, United States; ${ }^{6}$ The University of Tokyo; ${ }^{7}$ Daiichi Sankyo Co. Ltd, Tokyo, Japan; ${ }^{8}$ University of California, San Francisco, United States; ${ }^{9}$ Leiden University Medical Center, Leiden, Netherlands

Background: Denosumab is a fully human monoclonal antibody (lgG ${ }_{2}$ subclass) that inhibits bone resorption by inhibiting RANKL, a key mediator of osteoclast formation, function, and survival.

Objectives: To evaluate the effect of denosumab $60 \mathrm{mg}$ every 6 months (Q6M) or every 3 months (Q3M) on the progression of joint damage in Japanese patients with RA on csDMARD background treatment.

Methods: DESIRABLE is a 12-month randomized, double-blind, placebocontrolled, parallel-group study in patients with RA receiving csDMARD treatment. Subjects fulfilling the 1987 ACR criteria or 2010 ACR-EULAR criteria were randomized (1:1:1) to denosumab $60 \mathrm{mg}$ Q6M, denosumab $60 \mathrm{mg}$ Q3M, or placebo. The primary endpoint is the change from baseline to 12 months in the van der Heijde modified total Sharp score (mTSS). Radiographs of hands and feet at baseline 6 months and 12 months were scored with blinded time order by 2 readers independently. Average score of the 2 readers is used for the analysis. Comparisons of each denosumab group with placebo for the change from baseline were performed using van Elteren stratified rank test adjusting for baseline glucocorticoid use. Missing scores were imputed using linear extrapolation/interpolation.

Results: Among 679 patients randomized, 667 (placebo, $n=223$; Q6M, $n=222$; $\mathrm{Q} 3 \mathrm{M}, \mathrm{n}=222$ ) received at least one dose of study drug, and 60 (placebo $\mathrm{n}=15$; Q6M, $n=23 ; \mathrm{Q} 3 \mathrm{M}, \mathrm{n}=22$ ) were discontinued during the study. Demographic and baseline characteristics were similar across the groups (Table 1). Mean change from baseline in mTSS and erosion score (ES) at 12 months was significantly lower with both denosumab $60 \mathrm{mg}$ Q6M and Q3M compared with placebo, with no obvious evidence of an effect on joint space narrowing (JSN) score for denosumab. (Table 2).

Consistently, the percent of nonprogressors (ie, mTSS change $\leq 0.5$ ) at 12 months was significantly greater with denosumab $60 \mathrm{mg} \mathrm{Q6M}(75.6 \%, \mathrm{p}=0.010)$ and Q3M (78.1\%, $\mathrm{p}=0.001)$ compared with placebo $(64.2 \%)$.

Incidence of adverse events (AEs), serious AEs, and AEs leading to discontinuation of study drug were similar across treatment groups. No events of osteonecrosis of the jaw or atypical femoral fracture were observed.

Table 1. Baseline demographics and characteristics

\begin{tabular}{|c|c|c|c|}
\hline \multirow[b]{2}{*}{ Characteristic } & \multirow[b]{2}{*}{$\begin{array}{l}\text { Placebo } \\
\mathrm{N}=\mathbf{2 1 8}\end{array}$} & \multicolumn{2}{|c|}{ Denosumab $60 \mathrm{mg}$} \\
\hline & & $\begin{array}{c}\text { Q6M } \\
\mathrm{N}=217\end{array}$ & $\begin{array}{c}\text { Q3M } \\
N=219\end{array}$ \\
\hline Female & $167(76.6)$ & $168(77.4)$ & $154(70.3)$ \\
\hline Age (years) & $55.8 \pm 11.7$ & $58.1 \pm 12.3$ & $58.2 \pm 12.0$ \\
\hline Disease duration (years) & $2.1 \pm 1.3$ & $2.2 \pm 1.3$ & $2.2 \pm 1.3$ \\
\hline Rheumatoid factor positive & $137(62.8)$ & $140(64.5)$ & $128(58.4)$ \\
\hline MTX use & $190(87.2)$ & $176(81.1)$ & $189(86.3)$ \\
\hline Glucocorticoid use & $69(31.7)$ & $73(33.6)$ & $68(31.1)$ \\
\hline DAS28-CRP & $3.4 \pm 1.0$ & $3.6 \pm 1.1$ & $3.5 \pm 1.0$ \\
\hline mTSS & $13.1 \pm 21.4$ & $15.9 \pm 22.2$ & $15.2 \pm 19.0$ \\
\hline
\end{tabular}

Data presented are Mean \pm SD or $n(\%)$.

Table 2. Change from baseline in mTSS, ES and JSN at 12 months

\begin{tabular}{|c|c|c|c|}
\hline \multirow[b]{2}{*}{ Characteristic } & \multirow[b]{2}{*}{$\begin{array}{l}\text { Placebo } \\
N=218\end{array}$} & \multicolumn{2}{|c|}{ Denosumab $60 \mathrm{mg}$} \\
\hline & & $\begin{array}{c}\mathrm{Q6M} \\
\mathrm{N}=217\end{array}$ & $\begin{array}{c}Q 3 M \\
N=219\end{array}$ \\
\hline mTSS & $1.49 \pm 3.76$ & $\begin{array}{l}0.99 \pm 3.77 \\
(p=0.024)\end{array}$ & $\begin{array}{l}0.72 \pm 2.32 \\
(p=0.006)\end{array}$ \\
\hline Erosion score & $0.98 \pm 2.48$ & $\begin{array}{l}0.51 \pm 2.15 \\
(p=0.010)\end{array}$ & $\begin{array}{l}0.22 \pm 0.95 \\
(p<0.001)\end{array}$ \\
\hline JSN score & $0.51 \pm 1.72$ & $\begin{array}{l}0.48 \pm 2.08 \\
(p=0.257)\end{array}$ & $\begin{array}{l}0.50 \pm 1.76 \\
(p=0.533)\end{array}$ \\
\hline
\end{tabular}

Data presented are Mean $\pm S D$

Conclusions: Denosumab inhibited the progression of joint destruction significantly more than placebo and was generally well tolerated in Japanese patients with RA on csDMARDs. Denosumab has potential to be a new therapeutic option to inhibit structural progression for patients with RA.

Disclosure of Interest: T. Takeuchi Grant/research support from: Astellas, BristolMyers Squibb, Chugai, Daiichi Sankyo, Eisai, AYUMI Pharmaceutical, Takeda, Teijin Pharma, AbbVie, Asahi Kasei Pharma, and Taisho Toyama, Consultant for: AstraZeneca, Eli Lilly, Novartis, Mitsubishi Tanabe, Asahi Kasei Pharma, AbbVie, Daiichi Sankyo, Bristol-Myers Squibb, Nipponkayaku, Janssen, Merck Serono, Takeda, Astellas, and Pfizer, Speakers bureau: AbbVie, Bristol-Myers Squibb, Chugai, Eisai, Janssen, Mitsubishi Tanabe, Pfizer, Takeda, Astellas, Daiichi Sankyo, Celtrion, and Nipponkayaku, Y. Tanaka Grant/research support from: BMS, MSD, Chugai, Mitsubishi Tanabe, Astellas, AbbVie, and Daiichi Sankyo, Speakers bureau: UCB Pharma, Mitsubishi Tanabe, Abbott, AbbVie, Eisai, Chugai, Janssen, Pfizer, Takeda, Astellas, Daiichi Sankyo, GSK, AstraZeneca, Eli Lilly, Quintiles, MSD, and Asahi Kasei Pharma, S. Soen Grant/research support from: Eisai, Daiichi Sankyo, and Takeda, Speakers bureau: Asahi Kasei Pharma, Astellas, Eisai, MSD, Ono Pharmaceutical, Daiichi Sankyo, Takeda, Chugai, Teijin 
Pharma, and Pfizer, H. Yamanaka Grant/research support from: UCB Pharma, AbbVie, Astellas, Bristol-Myers Squibb, Chugai, Eisai, Janssen, Mitsubishi Tanabe, Pfizer, and Takeda, Consultant for: UCB Pharma, AbbVie, Astellas, Bristol-Myers Squibb, Chugai, Eisai, Janssen, Mitsubishi Tanabe, Pfizer, and Takeda, T. Yoneda Consultant for: Daiichi Sankyo, S. Tanaka Consultant for: Amgen inc, Amgen Astellas, KYOCERA Medical, Daiichi Sankyo, Teijin Pharma, Asahi Kasei Pharma, Ono Pharmaceutical, Eli Lilly, and Pfizer, T. Nitta Employee of: Daiichi Sankyo, N. Okubo Shareholder of: Daiichi Sankyo, Employee of: Daiichi Sankyo, H. K. Genant Consultant for: Daiichi Sankyo, Pfizer, Amgen, BioClinica, Eli-Lilly, Janssen, Servier, Novartis, Takeda, Merck, Biomarin, Clemencia, Agnovos, and Regeneron, D. van der Heijde Consultant for: AbbVie, Amgen, Astellas, AstraZeneca, BMS, Boehringer Ingelheim, Celgene, Daiichi Sankyo, Eli-Lilly, Galapagos, Gilead, Janssen, Merck, Novartis, Pfizer, Regeneron, Roche, Sanofi, and UCB Pharma, Employee of: Imaging Rheumatology bv DOI: 10.1136/annrheumdis-2017-eular.1081

\section{SAT0187 SAFETY, PHARMACOKINETICS AND EFFICACY OF E6011, AN ANTI-FRACTALKINE MONOCLONAL ANTIBODY, IN A FIRST-IN-PATIENT PHASE 1/2 STUDY IN RHEUMATOID ARTHRITIS; ADDTIONAL DATA OF 400 MG COHORT}

Y. Tanaka ${ }^{1}$, T. Takeuchi ${ }^{2}$, H. Umehara ${ }^{3}$, T. Nanki ${ }^{4}$, N. Yasuda ${ }^{5}$, F. Tago ${ }^{6}$, Y. Kitahara ${ }^{6}$, M. Kawakubo ${ }^{6}$, S. Hojo ${ }^{6}$, T. Kawano ${ }^{5}$, T. Imai ${ }^{5}{ }^{1}$ University of Occupational and Environmental Health, Japan, Kitakyushu; ${ }^{2}$ Keio University, Tokyo; ${ }^{3}$ Division of Rheumatology and Immunology, Nagahama City Hospital, Shiga; ${ }^{4}$ School of Medicine, Faculty of Medicine, Toho University, Tokyo; ${ }^{5}$ KAN Research Institute, Inc., Kobe; ${ }^{6}$ EISAI Co. Ltd., Tokyo, Japan

Background: Fractalkine (CX3CL1, designated as FKN hereafter) is the sole member of the CX3C-chemokine which leads to dual actions, chemotaxis and cell adhesion for leukocytes expressing the cognate receptor, CX3CR1, during their migration. Accumulating evidence is telling that FKN-CX3CR1 axis plays a pivotal role in leukocyte/lymphocyte accumulation in inflamed tissues in RA ${ }^{1}$. Last year, we presented an interim report (up to $200 \mathrm{mg}$ cohort) of Phase 1/2 study of E6011, a novel humanized anti-FKN monoclonal antibody, for active Japanese RA patients ${ }^{2}$.

Objectives: To evaluate safety, pharmacokinetics and efficacy of E6011 with the dosage up to $400 \mathrm{mg}$ in a Phase $1 / 2$, open-label, multiple ascending dose study in RA patients (NCT02196558).

Methods: Active RA patients with inadequate response (IR) to MTX or TNF inhibitors (TNFi) were received 7 consecutive doses (subcutaneous) of E6011 at week $0,1,2$ and thereafter every 2 weeks up to week 10 . The safety, pharmacokinetics and efficacy up to week 12 were evaluated.

Results: Twelve, 15 and 10 subjects were enrolled in the cohort of 100,200 and $400 \mathrm{mg}$ dosage, respectively, in total 37 subjects received repeated subcutaneous (SC) administrations of E6011. As a result, repeated dose of E6011 was found safe and well tolerated. The incidence of adverse event (AE), treatment-related $A E$ and serious $A E$ were $56.8 \%, 29.7 \%$ and $5.4 \%$, respectively. AEs occurring in $\geq 2$ subjects were nasopharyngitis, Injection site erythema, headache and oropharyngeal pain, among which there were no severe AEs, serious infections and deaths. No significant differences were observed in the incidence or severity of AEs across the cohorts.

After starting multiple SC injection of E6011, serum E6011 concentration reached steady-state at week 2, and its level was maintained up to week 12 in all cohorts. Clinical outcome was also available in the study in which response rates of ACR20, 50 and 70 at week 12 calculated using the non-responder imputation (NRI) were $75.0 \%, 33.3 \%, 8.3 \%$ in $100 \mathrm{mg}$ cohort, $66.7 \%, 20.0 \%, 13.3 \%$ in $200 \mathrm{mg}$ cohort and $60.0 \%, 30.0 \%, 20.0 \%$ in $400 \mathrm{mg}$ cohort, respectively. The percentage of patients categorized "good response" with the EULAR response criteria at week 12 (NRI) were $16.7 \%$ in $100 \mathrm{mg}$ cohort, $20 \%$ in $200 \mathrm{mg}$ cohort and $40 \%$ in $400 \mathrm{mg}$ cohort.

Conclusions: E6011 was safe and well tolerated, and the study demonstrated

Bar Chart of ACR Response Rate at Week 12 (NRI) Full Analysis Set

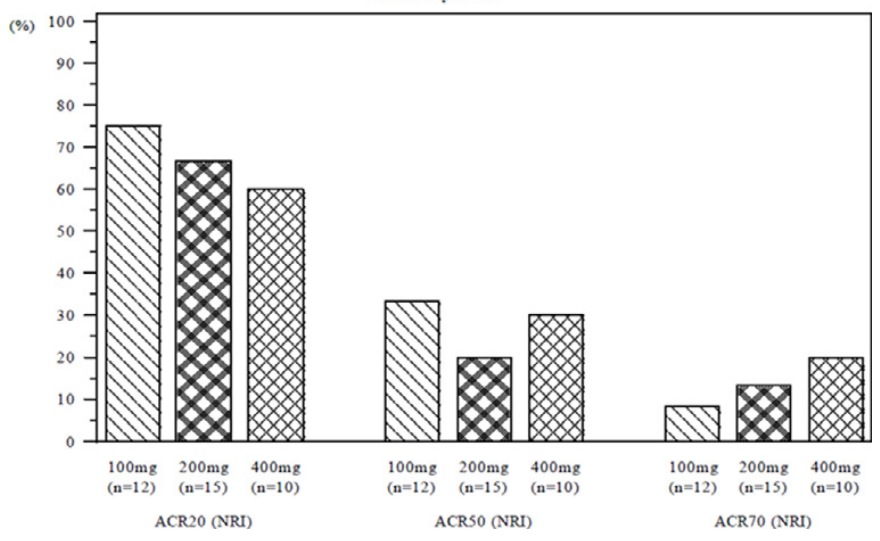

a promising efficacy of E6011 in active RA patients with MTX- or TNFi-IR. The results obtained suggest that a novel approach to target FKN/CX3CR1 interaction will be clinically beneficial for RA, and support to conduct phase 2 clinical trials in which the efficacy and safety should be confirmed in a placebo controled double-blind manner.

\section{References:}

[1] Nanki T. Arthritis Rheum. 2002; 46(11):2878-83.

[2] Tanaka Y, et al., EULAR Congress 2016, Poster Number FRI0236.

Acknowledgements: The authors wish to thank the study investigators.

Disclosure of Interest: Y. Tanaka Grant/research support from: MitsubishiTanabe, Takeda, Daiichi-Sankyo, Chugai, Bristol-Myers, MSD, Astellas, Abbvie, Eisai, Speakers bureau: Abbvie, Chugai, Daiichi-Sankyo, Bristol-Myers, MitsubishiTanabe, Astellas, Takeda, Pfizer, Teijin, Asahi-kasei, YL Biologics, Sanofi, Janssen, Eli Lilly, GlaxoSmithKline, T. Takeuchi Grant/research support from: Astellas, Bristol-Myers, Chugai, Daiichi-Sankyo, Eisai, AYUMI, Takeda, Teijin, AbbVie, Asahikasei, Taisho-Toyama, Consultant for: Astra Zeneca, Eli Lilly, Novartis, Mitsubishi-Tanabe, Asahi-Kasei, AbbVie, Daiichi-Sankyo, Bristol-Myers, Nipponkayaku, Janssen, Merck Serono, Takeda, Astellas, Pfizer, Speakers bureau: AbbVie, Bristol-Myers, Chugai, Eisai, Janssen, Mitsubishi-Tanabe, Pfizer, Takeda, Astellas, Daiichi-Sankyo, Celtrion, Nipponkayaku, H. Umehara: None declared, T. Nanki Grant/research support from: Chugai, Eisai, Takeda, Teijin, Eli Lilly, Bristol-Myers, AbbVie, Ono, Novartis, Asahi-Kasei, Consultant for: UCB, Eisai, Chugai, Speakers bureau: Mitsubishi-Tanabe, Chugai, Eisai, Takeda, Astellas, Janssen, Eli Lilly, Ayumi, Pfizer, Ono, AbbVie, N. Yasuda Shareholder of: EISAI, Employee of: EISAI, F. Tago Employee of: EISAI, Y. Kitahara Shareholder of: EISAI, Employee of: EISAI, M. Kawakubo Shareholder of: EISAI, Employee of: EISAI, S. Hojo Employee of: EISAI, T. Kawano Employee of: KAN Research Institute, T. Imai Employee of: KAN Research Institute DOI: 10.1136/annrheumdis-2017-eular.1401

\section{SAT0188 FIRST-LINE TREATMENT PATTERNS OF PATIENTS WITH RHEUMATOID ARTHRITIS WHO ARE ANTI-CYCLIC CITRULLINATED PEPTIDE ANTIBODY POSITIVE VERSUS NEGATIVE}

K. Price ${ }^{1}$, Y. Doleh ${ }^{1}$, M. Eaddy ${ }^{2}$, A. Ogbonnaya ${ }^{2}$, H.-C. Shih ${ }^{2}$, H. Ahmad ${ }^{1}$, L. Lamerato ${ }^{3}$, A. Szymialis ${ }^{1}{ }^{1}$ Bristol-Myers Squibb, Princeton; ${ }^{2}$ Xcenda, LLC, Palm Harbor; ${ }^{3}$ Henry Ford Health System, Detroit, United States

Background: Patients with RA who are at a higher risk for progressive and destructive arthritis could be identified using anti-cyclic citrullinated peptide (anti-CCP) levels. ${ }^{1}$ Treatment guidelines recommend the use of non-biologic DMARDs as initial treatment in RA; but, if warranted, biologic (b)DMARDs could be considered in early treatment of RA. ${ }^{2}$ Real-world data describing treatment patterns based on anti-CCP designations are limited.

Objectives: This study evaluated treatment patterns of patients with RA who are anti-CCP positive $(+)$ or negative $(-)$.

Methods: This retrospective study was based on electronic medical record (EMR) data with a supplemental chart review from a large integrated delivery system. Patients newly diagnosed with RA (International Classification of Diseases, Ninth Revision, Clinical Modification diagnosis code 714.0x) were identified between 1 January 2009 and 31 December 2014. The first RA diagnosis date was designated as the index date. Patients were required to have 12 months of continuous activity in the EMR (6 months pre- and 6 months post-index). Based on the baseline anti-CCP test results, patients were categorized as anti-CCP+ $(>7.0 \mathrm{U})$ or antiCCP- $(<7.0 \mathrm{U})$. First-line therapy (time to treatment initiation, treatment regimen, treatment changes and response to treatment) was evaluated in the post-index period. Response to treatment was determined based on physicians' notes.

Results: Overall, 217 anti-CCP+ and 191 anti-CCP- patients with RA were included in this study. A higher proportion of anti-CCP+ $(153,70.5 \%)$ than antiCCP-patients $(44,23.0 \% ; \mathrm{p}<0.0001)$ initiated treatment, generally within 1 month after diagnosis (anti-CCP+, mean [SD]: 31.1 [42.1] days and anti-CCP-, 28.1 [37.4] days; $p=0.6538$ ). MTX was most commonly used as first-line therapy. More anti-CCP+ than anti-CCP- patients received MTX (73.2 vs $56.8 \%$; $\mathrm{p}=0.0374)$, while more anti-CCP-than anti-CCP+ patients received hydroxychloroquine (31.8 vs $13.1 \% ; p=0.0037$ ). Only three anti-CCP+ and no anti-CCP- patients were treated with a bDMARD. Response to treatment was similar between the cohorts $(p=0.2444) ; 22.9 \%$ of anti-CCP+ and $18.2 \%$ of anti-CCP-patients had a complete response to the first-line therapy, and $33.3 \%$ of anti-CCP+ and $25.0 \%$ of antiCCP- patients had a partial response to the first-line therapy. Treatment change, however, significantly differed between the two cohorts ( $p=0.0058) ; 11.1$ and $9.1 \%$ of patients discontinued, 9.8 and $9.1 \%$ of patients switched, and 3.9 and $9.1 \%$ of patients augmented in the anti-CCP+ and anti-CCP- cohorts, respectively. Treatment changes occurred approximately 3 months after treatment initiation (anti-CCP+, 82.0 [49.7] days and anti-CCP-, 83.8 [52.7] days; $\mathrm{p}=0.9178$ ).

Conclusions: After diagnosis of RA, patients who are anti-CCP+ were more likely to start therapy, indicating that physicians were more aggressive in treating this cohort. Patients were treated according to guidelines with non-biologic DMARDs, predominantly MTX. Patterns of treatment change differed between the cohorts; however, treatment response was similar with a complete response rate of $20 \%$. References:

[1] Singh JA, et al. Arthritis Rheumatol 2016;68:1-26.

[2] Niewold TB, et al. QJM 2007;100:193-201. 